\title{
Three-dimensional magnetic resonance reconstruction images before and after surgical therapy of spontaneous canine brain tumors
}

\author{
Imagens de reconstrução tri-dimensional por ressonância magnética antes e depois de tratamento \\ cirúrgico de tumores cerebrais espontâneos caninos
}

Julio Carlos Canola ${ }^{\mathrm{I}}$ Fabrício Singaretti de Oliveira ${ }^{\mathrm{II}}$

- NOTE -

\section{ABSTRACT}

Specific software was used for reconstruction of spontaneous intracranial tumor volume from magnetic resonance images (MRI) in three dogs. Histopathologically confirmed meningioma, cystic meningioma, and choroid plexus tumors were evaluated before and after surgery. The software allowed the whole-volume segmentation of the skin, brain, tumor, edema, and cyst. Manipulation of the three-dimensional images (3D) allowed visualization of all anatomical structures, aided clinical understanding, surgical planning, and treatment monitoring.

Key words: image segmentation, magnetic resonance, brain tumor, dog.

\section{RESUMO}

Um programa de computador específico foi utilizado para reconstrução do volume tumoral intracraniano espontâneo por imagens de ressonância magnética (IRM) em três cães. Tumores histopatologicamente confirmados como meningioma, meningioma cístico e tumor do plexo coróide foram avaliados antes e após cirurgia. O programa de computador permitiu a segmentação por completo da pele, do cérebro, do tumor, do edema e do cisto. A manipulação das imagens tridimensionais permitiu a visibilização de todas as estruturas anatômicas, além da compreensão clínica, do planejamento cirúrgico e da monitorização do tratamento.

Palavras-chave: segmentação de imagem, ressonância magnética, tumor cerebral, cão.
Intracranial tumors are relatively common in dogs and less common in cats (BURK, 1997). Spontaneous canine intracranial tumors have similar rates of frequency brain tumors in people (KRAFT et al., 1990). Intracranial tumors include tumors that arise from ectoderm or mesoderm (BURK, 1997). Primary brain tumors in dogs may be meningiomas, astrocytomas, neuroblastomas, oligodendrogliomas, or ependymomas (FOSTER et al., 1988). Meningiomas, followed by astrocytomas, are reported to be the most common intracranial tumors of older dogs and cats (FOSTER et al., 1988; TURREL et al, 1986).

The purpose of this article is to demonstrate the use of three-dimensional (3D) image construction to depict brain tumors, peritumoral edema, and brain anatomy from MR images. The 3D images aid in clinical understanding and surgical planning.

Three dogs with primary intracranial tumors were selected for study. Only dogs with MR images obtained before and after surgery were included. Dogs ranged at age from 7 to 10 years; 2 were female, and 1 was male. All three animals with clinical central nervous system disease were obtained from referring veterinarians. Histologic confirmation of a primary intracranial tumor was required for inclusion in this study. Diagnosis was based on histologic examination of brain tissue obtained at surgery and necropsy.

'Departamento de Clínica e Cirurgia Veterinária, Setor de Diagnóstico por Imagem, Faculdade de Ciências Agrárias e Veterinárias, Universidade Estadual Paulista (FCAV/UNESP), Campus Jaboticabal, SP, Brasil. Via de Acesso Paulo Donato Castelane, s/n, 14883-800. E-mail: canola@fcav.unesp.br. Autor para correspondência.

"Laboratório de Anatomia Animal, Faculdade de Medicina Veterinária, Universidade Estadual de Maringá (UEM), Campus Umuarama, PR, Brasil. 
Cerebrospinal fluid (CSF), routine hematological and biochemical evaluation were performed on each dog before MR imaging. Images were obtained by a high field-strength MR scanner with 1.0-Tesla (T) MR unit (Gyroscan NT Release 4.5 Philips), housed at Washington State University Veterinary Medical Teaching Hospital (WSU-VMTH).

Anesthesia was induced with intravenous infusion of thiamylal and maintained with isoflurane mixed in oxygen using an open anesthesia circuit system. Dogs were placed in sternal recumbency on the scanning table and a human quadrature knee coil was used.

A three plane localizer series was used to delineate the image slices desired for each pulse sequence series. Repetition time (TR) was $11 \mathrm{~ms}$, echo delay time (TE) was $4.2 \mathrm{~ms}$, and the flip angle (FA) was 60 degrees. Section width (SW) for sagittal images was $3.5 \mathrm{~mm}$, with an interslice gap of $0.35 \mathrm{~mm}$. A series of transverse slices was obtained from the region $3 \mathrm{~cm}$ rostral to the cribriform plate to the caudal aspect of the caudal fossa. A dual echo series with TR of $2000 \mathrm{~ms}$ and TE of both 28 (proton density image) and 110 (moderately T2-weighted images) was used. The field of view (FOV) was 170 - 230mm with a 205 x 256 matrix. Pre and postcontrast enhanced slices were obtained using a TR of $500-650 \mathrm{~ms}$ and a TE of $15 \mathrm{~ms}$ (T1weighted image). Paramagnetic contrast medium, gadolinium DTPA-dimeglumine (Magnevist, Berlex Laboratories, Inc., Cedar Knolls, NJ) $0.5 \mathrm{M}$ at $0 .{ }^{1 \mathrm{mmol}} . \mathrm{Kg}$ ${ }^{1}$ was given intravenously as a bolus prior to obtaining the enhanced MR images scan.

Three-dimensional images were constructed using a commercially available system (Easy Vision CT/ MR R2 - Philips software). In order to construct 3D images, each case was selected from the database. The software segmentation functions were used to isolate the object from the volume data in order to visualize them separately or in relation to the other objects. All objects received the following corresponding names: brain, cyst, edema, skin, tumor, and venogram.

The three reported canine cases occurred in a Golden Retriever (male, 10-year-old, with behavior change and aggressiveness - dog number 1), Labrador Retriever and Shetland Sheepdog (both spayed female, 7-year-old, with ataxia - dogs number 2 and 3, respectively). The primary clinical complaint in these dogs was noticed approximately three months before the first MRI scan. Time between the MRI scan diagnosis and surgery procedure ranged from 1 to 5 days. Biopsy was performed during surgery and the final diagnosis was Meningioma (dog number 1), cystic meningioma (dog number 2) and choroid plexus tumor (dog number 3).

A summary of the MRI scan characteristics and location of brain tumors, before surgery, is provided in table 1 . On the T1-weighted noncontrast images, decreased signal intensity was found in one dog (2), while in the other two dogs (1 and 3) no change in signal intensity was seen at the tumor site. Increased signal intensity was observed at the tumor site in the T2-weighted images in all three dogs. All three tumors were considered to have marked enhancement on the images obtained after intravenous administration of contrast agent. All three tumors were localized in different regions of the brain, had different shapes, and did not appear to invade adjacent bone before surgery. Minimal edema was present in the choroid plexus tumor on dog 3. Minimal to medium mass effect was present in all three tumors; hydrocephalus was observed in the brain containing the choroid plexus tumor.

A summary of the tumor volume, edema volume, and cystic volume is provided in table 2 . All three tumors could not be removed completely during the surgery; consequently some MRI characteristics were present immediately after surgery therapy. Edema was observed at the tumor site even after surgery in

Table 1 - Summary of magnetic resonance imaging characteristics and location of brain tumor before surgery.

\begin{tabular}{|c|c|c|c|c|c|c|}
\hline \multirow{2}{*}{ Dog No } & \multicolumn{2}{|c|}{ Signal intensity } & \multirow{2}{*}{ Enhancement } & \multirow{2}{*}{ Location } & \multirow{2}{*}{ Edema } & \multirow{2}{*}{ Cyst } \\
\hline & T1-WI & T2-WI & & & & \\
\hline 1 & Equal & Incr & $\begin{array}{l}\text { Marked, homogeneous } \\
\text { well-defined, irregular }\end{array}$ & $\begin{array}{l}\text { Left side of ventral } \\
\text { midbrain }\end{array}$ & None & None \\
\hline 2 & Decr & Incr & $\begin{array}{l}\text { Marked, honogeneous } \\
\text { ill-defined, smooth }\end{array}$ & Left side of cerebellum & None & Present \\
\hline 3 & Equal & Incr & $\begin{array}{l}\text { Marked, homogeneous } \\
\text { well-defined, irregular }\end{array}$ & $\begin{array}{l}\text { Left side of forth } \\
\text { ventricle }\end{array}$ & Marked & None \\
\hline
\end{tabular}

Decr: decreased; Incr: increased. 
Table 2 - Summary of tumor, edema, and cyst volume $\left(\mathrm{cm}^{3}\right)$ obtained by magnetic resonance imaging.

\begin{tabular}{|c|c|c|c|c|c|c|}
\hline \multirow{2}{*}{ Dog No. } & \multicolumn{3}{|c|}{ Before surgery } & \multicolumn{3}{|c|}{ After surgery } \\
\hline & Tumor & Edema & Cyst & Tumor & Edema & Cyst \\
\hline 1 & 7682.9 & None & None & 6737.5 & None & None \\
\hline 2 & 244.5 & None & 4420.1 & 154.6 & None & None \\
\hline 3 & 1881.2 & 2772.0 & None & 900.4 & 2624.3 & None \\
\hline
\end{tabular}

the dog with the choroid plexus tumor, while the cystic portion was removed from the site in the dog with the cystic meningioma. When edema surrounded the tumor, the actual volume corresponded to the edema volume, from the T2-weighted image, minus the volume of tumor mass from the T1-weighted postcontrast image. Routine hematologic, biochemical, and urinalysis results, and CSF analysis were within normal levels in all three dogs.
A 2D view from dog 3 was obtained before surgery, and after reconstruction of tumor and edema volumes. Both tumor and edema hidden in the brain are shown and the isolated tumor from other tissues is seen (Figure 1). After surgery, neurological abnormalities increased during a month in all three dogs, so euthanasia and necropsy were performed.
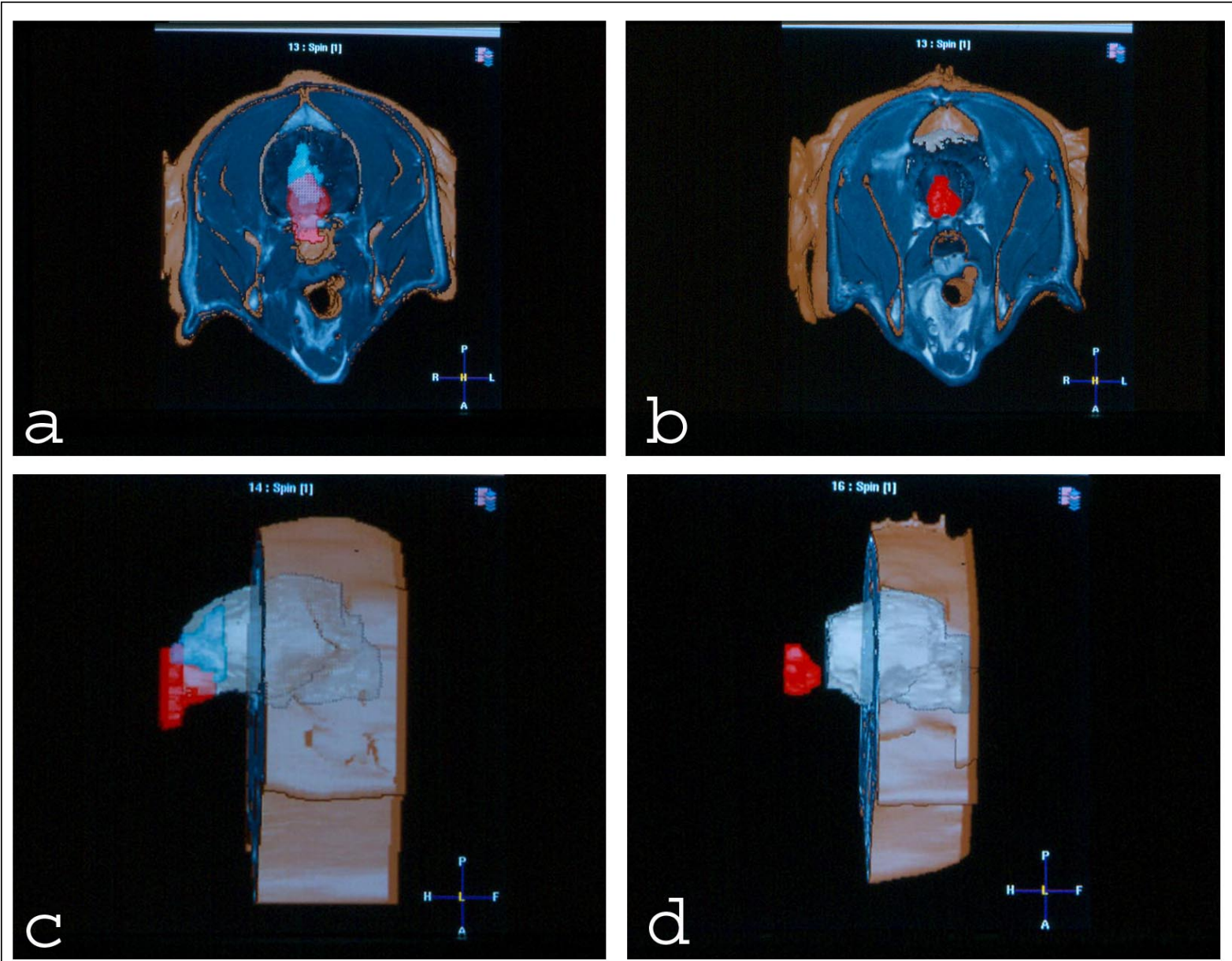

Figure 1 - T2-weighted cranium transverse image in rostrocaudal (a) and laterolateral (c) views from dog number 3 . There are shown a tumor (red) and its edema (blue) before surgery. Images immediately after surgery are shown in rostrocaudal (b) and laterolateral (d) views and present a smaller tumor (red); the edema was taken out by the software for better visibilization of the tumor. 
Meningioma has been the intracranial tumor type most frequently diagnosed (FOSTER et al., 1988), however cystic meningioma was uncommon in dogs (SCHULMAN et al., 1990). A cyst, within or associated with meningioma, may be related to tumor necrosis or degeneration (ELSTER et al., 1989).

Edema may be present with meningiomas (DEAN et al., 1990), whereas minimal peritumoral edema was observed in choroid plexus tumors (TURREL et al., 1986). T2-weighted images were used to reconstruct edema volume because edema is better seen in T2weighted sequence (DEAN et al., 1990). On the other hand, the software used offers various methods that facilitate the evaluation of the difference between two volumes by combining of the volumes into a single view. These functions were used to establish the precise contour of each reconstructed volume (SAEED et al., 1997).

Three-dimensional reconstruction images represented an important aid in the interpretation of tomographic data (SALAMON et al., 1991). Accurate localization of brain tumors is very important from the therapeutic point of view. Neurosurgical intervention has been considered essential in the management of the intracranial tumors, whether for complete or partial excision or biopsy (NEIBAUER et al., 1991). The differentiation of tumor tissue from peritumoral edema may be extremely important if surgery is the treatment (STEWART et al., 1992).

This paper presents a preliminary experience with three-dimensional images using specific software to reconstruct spontaneous brain tumors, in dogs, from MRI images. Tumor, edema, cyst, veins, and normal structures can be visualized in three dimensions. Color improves the visualization of segmented volumes, while gradient transparency enhances the perception of depth. Manipulation of the 3D images aids surgical planning, and tumor volume indexing can be followed up after surgery and/or radiation therapy.

\section{ACKNOWLEDGEMENTS}

This research was sponsored by FAPESP (Fundação de Amparo à Pesquisa do Estado de São Paulo), process number 19960606-2.

\section{REFERENCES}

BURK, R.L. Neuroradiation oncology. Veterinary Clinics of North America: Small Animal Practice, v.27, p.95100, 1997.

DEAN, B.L. et al. Gliomas: classification with MR Imaging. Radiology, v.174, p.411-415, 1990.

ELSTER, A.D. et al. Meningiomas: MR and histopathologic features. Radiology, v.170, p.587-862, 1989.

FOSTER, E.S. et al. Clinical signs of tumors affecting the rostral cerebrum in 43 dogs. Journal of Veterinary Internal Medicine, v.2, p.71-74, 1988.

KRAFT, S.L. et al. Diffuse cerebral and leptomeningeal astrocytoma in dogs: MR features. Journal of Computer Assisted Tomography, v.14, p.555-560, 1990.

NEIBAUER, G.W. et al. Evaluation of craniotomy in dogs and cats. Journal of the American Veterinary Medical Association, v.198, p.89, 1991.

SAEED, $\mathrm{N}$ et al. Automated brain segmentation from single slice, multislice, or whole-volume MR scans using prior knowledge. Journal of Computer Assisted Tomography, v.21, p.192-201, 1997.

SALAMON, G. et al. Topographical study of supratentorial brain tumors. Journal of Neuroradiology, v.18, p.123-140, 1991.

SCHULMAN, F.Y. et al. Cystic papillary meningioma in the sella turcica of a dog. Journal of the American Veterinary Medical Association, v.200, p.67-69, 1990.

STEWART, W.A. et al. The use of magnetic resonance imaging in the diagnosis of neurological disease. Canadian Veterinary Journal, v.33, p.585-590, 1992.

TURREL, J.M. et al. Computed tomographic characteristics of primary brain tumors in 50 dogs. Journal of the American Medical Association, v.188, p.854-856, 1986. 